\title{
MODADA SÜRREALIZM
}

\author{
Başak BOĞDAY SAYĞILI
}

Dr. basakbs(at)gmail.com

Boğday, Sayğılı, Başak “Modada Sürrealizm” idil, 61 (2019 Eylül): s. 1091 -1099 . doi: 10.7816/idil-08-61-03

\section{$\ddot{O} z$}

Moda ve sanat kavramları çoğu zaman bir arada kullanılmaktadır. Moda olgusunun ortaya çıktı̆̆1 19.yüzyılın ikinci yarısından günümüze kadar moda ve sanat etkileşimi birçok çalışmanın, araştırmanın konusu olmuştur. Giysinin, tasarım ilke ve yöntemlerine göre hazırlanarak bir tasarıma dönüşmesinden itibaren sanat ile ilişkisi başlamıştır. Bu durum giysinin, sanatın içinde yer almasına ve sanat akımlarından etkilenmesine neden olmuştur. Bu araştırmanın amacı; sürrealizm (gerçeküstücülük) sanat akımının etkilerinin görülmeye başlandığı 1920'li yılların başından günümüze kadar olan süreçte modadaki etkilerini örneklerle açıklamaya çalışmaktır.

Anahtar Kelimeler: moda, sanat, sürrealizm, moda tarihi

Makale Bilgisi

Geliş: 7 Ekim 2018
Düzeltme: 8 Mart 2019

Kabul: 11 Ağustos 2019 


\section{Giriş}

Sanat; insanın iç dünyasını, doğayı algılayıș biçimini, insan yaşamını, insanın yaşadığı toplumu, sosyolojik, ekonomik ve politik dönemi yansitan en önemli araçlardan biridir. Sanatın değişim seyri insanlığın gelişim belgeleri niteliğindedir. Dönemin şartlarına göre şekillenen sanat, kendini üreten çevreyle ve üretildiği zamanla denge içindedir (Ünver, 2015:190-193). Sanat; plastik, görsel, müzik ve edebiyatı içermektedir. Müzikte olduğu gibi bütün sanat dallarındaki sanatçılarda hoşa gitme isteği vardır. $\mathrm{Bu}$ istek, sanat objesinin sanat1 takip edenler tarafından beğenilme, hoşa gitme isteğiyle daha güzele erişme çabasıdır (Read, 2014:11). Her alanda güzele ulaşma çabası estetik sonuçları ortaya çıkarmaktadır.

1800'lerin sonunda yaşanan sanayi devrimi ile II. Dünya Savaşı arasında yaşanan kapitalizm ve ticarileşme, toplum düzeninde köklü değişimler ortaya çıkarırken, sanat dünyasında da önemli değişimlere sebep olmuştur. Sanayi devrimine kadar görüneni ya da bilineni en iyi şekilde vermeyi hedefleyen resim sanatının yerini, fotoğraf makinasının gelişmesi ile fotoğraf makinası almıştır. Fotoğraf makinasının ürünü olan fotoğrafın, nesnel bir kanıt olarak icat edilmesinden bu yana birtakım ideolojik ve estetik stratejilere ihtiyac1 bulunmaktadır (Özdemir, Mutlu 2017:654). Bu ihtiyaç doğrultusunda fotoğraf sanatı gelişmiştir. Fotoğraf sanatının gelişmesi üzerine resim sanatında büyük değişimler yaşanmıştır. Resim sanatında görünen ya da bilineni farklı şekillerde ifade etmenin yolları olarak modern sanat akımları ortaya çıkmıştır. Sanat artık modern sanat olarak nitelendirilmeye başlanmış ve sanatın ne olduğuna ilişkin yerleşik anlayış değişmeye başlamıştır (Grzymkowski, 2015:162). Bu dönemde başlayan bu kültürel dönüşüm, yaratıcı yaklaşımlar ve yorumlar pek çok yeni akımı ortaya çıkarmıştır. Bunlardan bazıları yeni izlenimcilik, sembolizm, fovizm, kübizm, fütürizm, dişavurumculuk, yapısalcılık, metafizik resim, dadaizm, sosyal gerçekçilik, soyut dişavurumculuk, pop art, yeni dişavurumculuk ve sürrealizmdir. Modern sanat akımlarından biri olan sürrealizm, görünen ya da bilinenin ötesinde sanatın ortaya çıkmasını sağlayanın bilinçaltı olduğunu belirtmektedir. Sürrealizm(Gerçeküstücülük), Fransız yazar ve şair André Breton'un 1924 tarihli manifestosuyla başlayan sanatsal ve düşünsel bir avangart harekettir. Sürrealizm, öngörülebilir mantığa ve Breton'un "gerçekçi tavır" dediği olguya karş1 çıkmakta, gerçekliği sıradan algılardan ve sanatla bağlantıdan kopartmaktadır (Grzymkowski,
2015:150). Sürrealistlerin; gerçeklik kavramını yansıtmak için kullandıkları otomatizm, düş kullanımları ve halüsinasyon yöntemlerinin ortak özelliği bireyin ön plana çıkarılmasıdır. Bireyin kendini keşfetme isteği, duygu ve ötesindeki arayışlarına neden olur (Türker, Çokokumuş, 2014:122). Sürrealizm bilinçaltının karanlık dünyasını yansıtmaktadır. Klee'nin deyimiyle "görüneni vermiyor, görünmeyeni görselleştiriyor". Sürrealizmin öncülerine göre, Sürrealizm: irade ve aklın ötesinde, bilinçaltı güçlerinin ahlak ve estetik değerleri yıkarak insan kişiliğini devirdiği ve onu "otomatizm"e sürüklediği yerde başlamaktadır (İpşiroğlu, 2012:186).

20. yüzyılda teknolojinin gelişmesi sanatı olumlu yönde etkilerken, II. Dünya Savaşı oldukça olumsuz etkilemiştir. Sürrealizm sanat akımı 1924'te resmi olarak başlayıp en yoğun olarak 1930-1940 yılları arasında etkili olmuştur. Ancak o dönem sonrasında da pek çok sanatçı ve tasarımcı Sürrealizmden etkilenerek sanat eserlerini ve tasarımlarını Sürrealizm çerçevesinde yansıtmaktadırlar. Bu durum aslında bir akımın başlangıç ve bitişinin keskin bir şekilde ifade edilemeyeceğini göstermektedir.

Kültür endüstrisinin bir parçası olan moda; örtünme, korunma ve isınmanın ötesinde bireysel ve toplumsal kimliği oluşturan sosyal ve politik sembolleri içeren bir iletişimdir. Giysilerle kişinin kendini ifade etmeye çalışma, toplumun içinde fark edilmesini sağlama ya da toplumun bir parçası olma çabası olan moda ile sanatın tanımı kesişmektedir. Sanat; kişinin kendi fikirlerini yansıtma ve bu fikirlerini yansıtırken kullandığı üsluptur. Güzel sanatlar, resim ve heykeli kullanma biçimlerine göre toplumlar birbirinden farklılaşmakta ve toplumların kendi uygarlıklarını diğerlerinden ayırmaktadır. Geçmişte ve günümüzde toplumlar kimliklerini yapılandırmak ve geleceğe iz bırakmak için farklı sanat ve tasarım ürünleri kullanırlar. Farklı biçimlerdeki kültürel ürünlerin varlıkları, farklı kültürlerin kimliklerini yapılandırma çabalarıdır (Barnard, 1998:69-187). Bu durum insan yapımı nesnelerin, sanat eserlerinin sahip olduğu özelliklerin bunları yapanların bulundukları toplum özelliklerini göstermektedir. Zaman, ekonomik benzerlik ve coğrafi alanlara göre benzerlik gösterse de, toplumlar arasında önemli farklılıklar bulunmaktadır. Wolff, sanatın toplumsal bir ürün olduğunu ve hatta sanatsal yaratıcılığın kavramlarını, sanatçı kavramının romantik dönemin bir ürünü olduğunu söyler (Wolff, 1992 aktaran: Barnard,1998:72). Sanatın bir ürün olduğu varsayıldığında da gelen "Moda" nın hem bir 
sanat hem de tasarım alanı olduğu kabul edilmesi gerekir. 1800'lü yılların sonunda İngiliz tasarımc1 Charles Frederick Worth'ün aslında haute couture'ü başlatması ve ilk moda evini açması modanın başlangıcı olarak kabul edilse de tarihe bakıldığında her dönemde giysiler, sanat akımlarından; resim, heykel vb. alanlar kadar etkilenmiştir. Charles Frederick Worth tablolardan esinlenerek daha düşsel tasarımlarıyla sanat ile moda arasında da önemli bir bağ kurmuştur (Kuru, 2010:509). Her sanat akımında, modanın çizgilerinde belirgin farkl1lıklar görülmüştür. Özellikle moda dehası olarak kabul edilen Paul Poiret'in "ben bir sanatçıyım, giysi üreticisi değil" sözü ile kendini sanatçı olarak tanımlamasından (Koç ve Emiroğlu, 2017) sonra moda tasarımcıları, moda ve sanat arasında çok daha yakın ilişkiler kurmuşlardır ve oluşturdukları koleksiyonlarda sanat akımlarından çok fazla etkilenmişlerdir.

Pek çok sanat akımının ortaya çıkış şehri olan Paris, modanın da en önemli merkezlerinden biridir (Granger, 2007:17). Moda, sanat ile aynı mekânda olmaktan dolayıda sanat akımlarından etkilenmiştir. Gerçeklerden kaçış ve hayal gücü eğilimlerinin ortaklığg nedeniyle sürrealizm ve moda doğal bir bağ içindedir. Sürrealist sanatçılar, moda endüstrisinin malzeme ve ürünlerini (özellikle cansız mankenlerini) kullanırken, modayı bilinç ile bilinçaltı arasındaki eşiği temsil etmek üzere kullanmışlardır (Mackenzie, 2017:78). Moda tasarımcıları, hangi dönemde olursa olsun giysileri tasarlarken algılarını zenginleştirir, gözlem ve hafızasını geliştirir, duygu ve düşüncelerini kullanırken (Koca, Koç, 2009:37), aynı zamanda yaratıcı olabilmek için çeşitli alanlara ilgi duyması ve farklı kaynaklardan beslenmesi gerekmektedir(Koç, Şoher, 2015:179).

1920'lerin sonunda avangart moda ile sürrealizmin kesişmesi, modernist hareketin işlevsel giysilerinin en büyük karşıt duruşuydu. Döneme damgasını vuran Sürrealizm sanat akımını modadaki ilk temsilcisi İtalya doğumlu tasarımc1 Elsa Schiaparelli'dir(1890-1973). Sürrealizmin temsilcisi olan Salvador Dali ile ortak çalışmalar yapan Elsa Schiaparelli modada sürrealizmi yaşatmıştır. Schiaparelli göz yanılsaması kullanarak triko tasarımında dünya çapında üne sahip olmuştur (Fogg, 2014:264). Tasarımcı sürrealist eğilimini siluette değil, ayrıntıda ortaya koymuştur. Schiaparelli moda tasarımının kendisi için bir meslek değil, farklı bir ifade aracı olduğunu savunmuştur. 1929 yılında ilk koleksiyonunu sunan tasarımcı el örgüsü kazaklar, montlar, etekler, mayolar ve tığ işi berelerden oluşan bir koleksiyon ortaya çıkard1. Schiaparelli, piyano ve ev telefonu gibi çanta ve aksesuarlar da sürrealist tasarımlar yapmıştır (Mackenzie, 2017:78).

1920-1930'larda sürrealizm aksesuar tasarımcılarını da oldukça etkilenmiştir. Sürrealist şapkalar, çantalar ve kolyeler en çok tercih edilen aksesuarlar olmuştur.

\section{Yöntem}

Moda tasarımcılarının sürrealizm sanat akımından etkilenerek tasarlamış oldukları giysilerin Sürrealizm Sanat Akımı'nın başlangıcından günümüze kadar ulaşılabilen belgeler doğrultusunda incelenmesi amacıyla yapılan bu nitel araştırmada; belgesel tarama yöntemi kullanılmıştır. Araştırmanın evrenini, Sürrealizm'in başlangıcı olarak kabul edilen 1924'ten günümüze kadar Sürrealizm'den etkilenerek tasarlanmış tüm moda giysi ve aksesuarları oluşturmaktadır. Araştırma örneklemini ise; bilinçaltının karanlık dünyasını yansıtan, görüneni değil, görünmeyeni görselleştiren sürrealist etkiyle tasarlanmış olduğu düşünülen giysilerin resimleri oluşturmaktadır.

\section{Bulgular}

Moda, iletişim teknolojisindeki ilerlemelerle fikirlerin ve görüntülerin çok kısa sürelerde dünya çapına yayıldığı günümüzde, tasarım sürecinde tasarımcılar doğadan, politikadan, ekonomiden, sanattan, kendi iç dünyalarından vs. pekçok kaynaktan beslenmektedir. Hislerini dışa yansıtmanın farklı biçimlerinden biri olan moda, sanatla çok yönde kesişmekte ve bu kesişme noktalarında birbirinden etkilenmektedir. Modada trend analizi yapıldığında yenilik arayan moda tasarımcılarının yada moda yöneticilerinin bulundukları sosyal çevreden ve moda alanındaki çevreden çok fazla etkilendikleri görülmektedir (Kim,Fiore, Kim, 2011:45). Çünkü yukarıda bahsettiğimiz gibi, sanatçı gibi moda tasarımcısıda toplumsal bir varlık ve ürettiği ürünlerde toplumsal ürünlerdir.

Sanat akımlarından, gerçeküstücülük olarakta ifade edilen sürrealizmin ortaya çıkışı olan 1924 yılından günümüze kadar olan sürede modada sürrealizm etkileri incelenmiştir.

Sürrealizmin temsilcisi olan Salvador Dali, Elsa Schiaparelli'nin tasarımlarının üzerine yaptığ çizimlerle sürrealizmin etkilerini modaya yansıtmıştır(Görsel 1). 


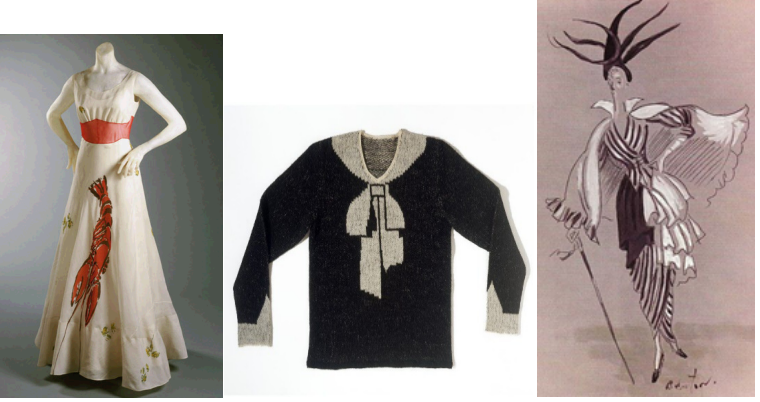

Görsel 1. http://www.artribune.com/tribnews/2012/07/artee-moda-eterne-sorelle-il-mumok-di-vienna-celebra-un-

sodalizio-vecchio-oltre-un-secolo-con-un-mostra-che-metteinsieme-christo-cindy-sherman-e-salvador-dali-nel-nome-delfashion/attachment/elsa-schiaparelli-salvador-dali-womansdinner-dress-1937-gift-of-mme-elsa-schiaparelli-1969philadelphia-museum-of-art/

Görsel 2. http://collections.vam.ac.uk/item/O15655/cravatjumper-elsa-schiaparelli/

Görsel 3.

https://www.pinterest.co.uk/pin/427349452115277480/

$\mathrm{Bu}$ dönem hem giyilebilir hem de sıradiş1 giysilerin zamanıyd1 (Watson, 2007:356). Sürrealizm ve modanın kesiştiği yıllar olan 1930'larda Salvador Dali ve Elsa Schiaparelli'nin yakın ilişkisi ile Schiaparelli, Sürrealist modada durdurulamaz bir güç haline dönüşmüştür. Trompel'oeil isimli sıradış1 sürrealist süveteri (Görsel 2) ile tanınan Elsa Schiaparelli, nakış, işleme teknikleri, küçük ve türban stili şapkaları, geniş omuzlu elbiseleri, yürüyüş paltolar1, ceketleriyle uyumlu kokteyl elbiseleri, atkıları, aksesuarları; balon şeklinde açılan eldivenleri fosforlu broşları, açılınca müzik çalan çantaları ile sürrealist moda ürünleri oluşturmuştur. Aynı zamanda tasarımc1 ilk "tema konsepti" hazırlayan moda tasarımcısı olmuştur (Dereboy, 2008:65-66).

Schiaparelli, Fransız kumaş üreticisi Charles Colocombet ile birlikte çalışmış ve dokulu kumaşlarla deneyler yaparak, sürrealist çalışmalar yapmıştır. Shiaparelli'nin yanı sıra Cecil Beaton (Görsel 3) gibi tasarımcılar Sürrealizmin etkisinde tasarımlar yapmışlardır.

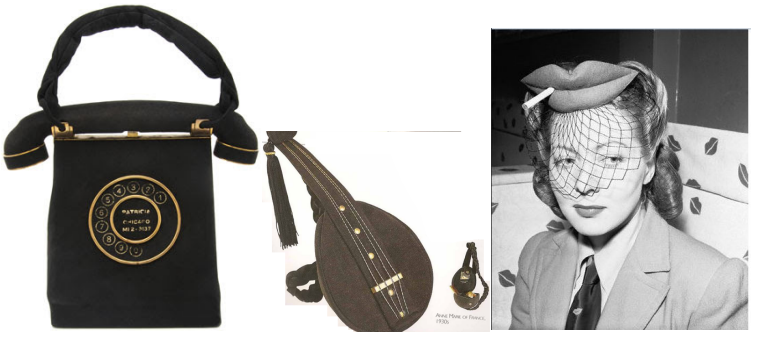

Görsel 4: http://kittyvonpurr.blogspot.com/2010/10/annemarie-of-paris-handbags.html

Görsel 5: http://kittyvonpurr.blogspot.com/2010/10/annemarie-of-paris-handbags.html

Görsel 6. https://tr.pinterest.com/pin/476114991827421845/

1930-1940 y1lları arasında aksesuar tasarımcıları da sürrealizmden oldukça etkilenmişlerdir. Sürrealist şapkalar, çantalar ve aksesuarlar (Görsel 4-5-6) tasarlanmıştır. Anne Marie of France'inin etkileyici aksesuar tasarımlarında sürrealizmden hatta Salvador Dali'den etkilenmiştir (Fogg, 2014: 263).

Samimi bir sürrealist olarak kendini tanımlayan Franco Moschino'nun, Elsa Schiaparelli ile diğer tasarımcılardan çok daha fazla ortak noktası bulunmaktadır. Tasarımlarının farklılığın yanı sıra tasarımlarının üzerine kelime oyunlarından yazılar yazmıştır. En son defílesinde "Less is More" yazan siyah ve kırmızı süslemeler kullanılmış bir yelek en dikkat çekici tasarımıdır (Görsel 7) (Watson, 2007:312).

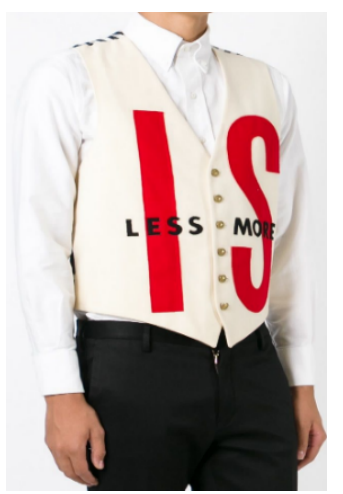

Görsel7.https://www.farfetch.com/tr/shopping/men/moschi no-vintage--less-is-more-gilet-item-11132856.aspx

Rene Magritte'ın 1935 yılında yaptığ “Kırmızı Model" isimli sürrealist tablosundan (Görsel 8) etkilenerek 1985 Yılında Pierre Cardin ayakkabı (Görsel 9) (Özüdoğru, 2013:223), 2009 yılında Comme Des Gargone Stiletto (Görsel 10) tasarlamıştır. 

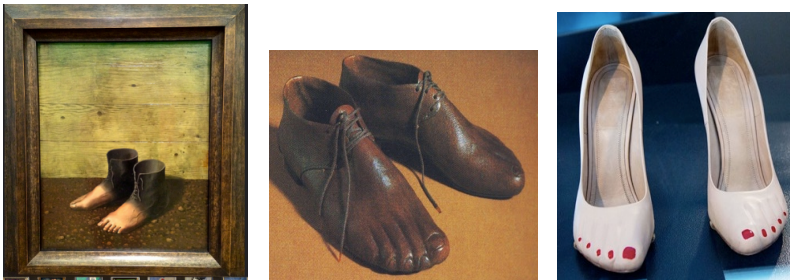

Görsel 8:

https://www.flickr.com/photos/azkaged/24509381522

Görsel 9: http://www.thehistorialist.com/2013/09/1971-joegarnett-for-records-surrealism.html

Görsel 10: http://www.thehistorialist.com/2013/09/1971-joegarnett-for-records-surrealism.html

Tasarımc1 Junya Watanabe ise giysi yapısında ve sunumunda sürrealist etkilerden faydalandığ1 düşünülebilir (Görsel 11-12) (Blackman, 2012:348).
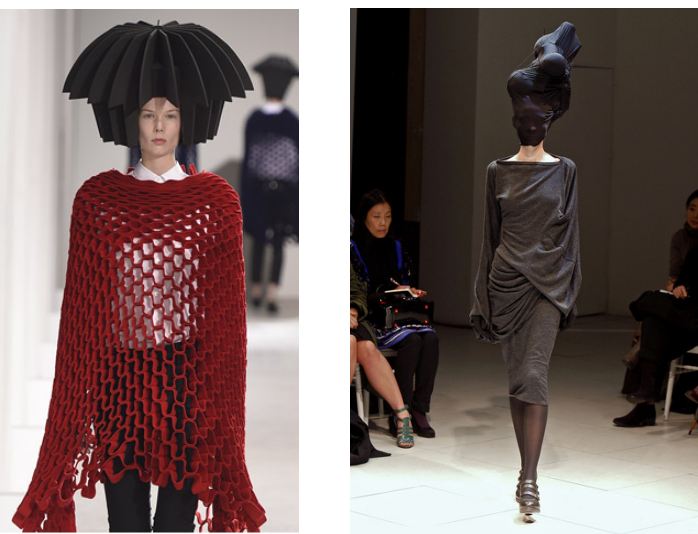

Görsel 11: https://www.dezeen.com/2015/03/10/junyawatanabe-aw15-paris-fashion-week-pleats-folds-mathematicalpatterns/

Görsel12.http://www.livingly.com/runway/Paris+Fashion+ Week+Fall+2008/Junya+Watanabe/_slhGXGjf_J

Balanciaga için çalışan tasarımcı Nicolas Ghesquiere 2010 da hazırladığ tasarımlarda sürrealist etkiler olduğu söylenebilir (Görsel 13-14-15).
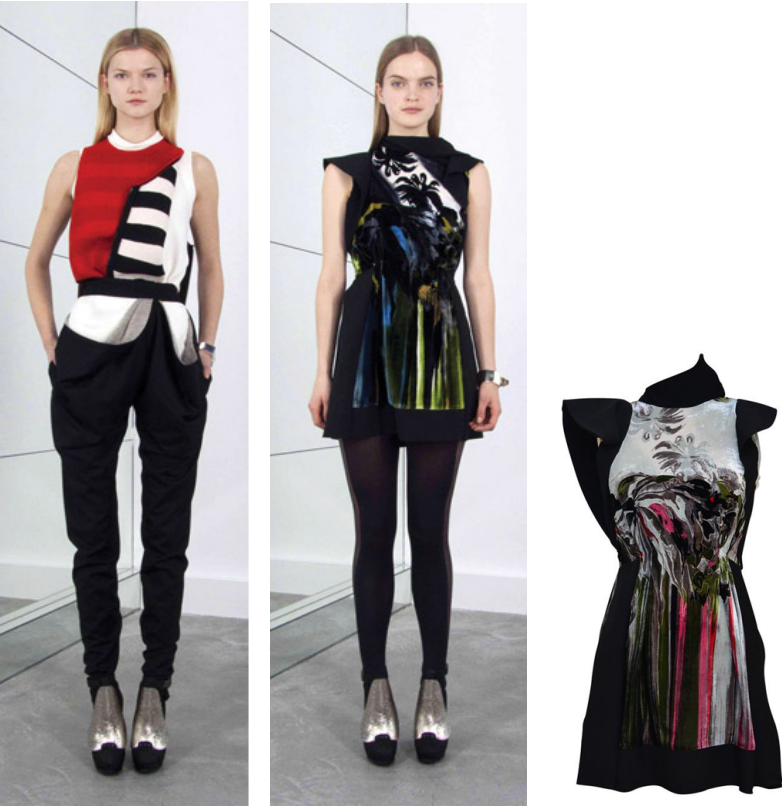

Görsel 13. https://nitrolicious.com/2010/01/14/balenciagapre-fall-2010-collection/

Görsel 14. https://nitrolicious.com/2010/01/14/balenciagapre-fall-2010-collection/

Görsel 15. https://www.1stdibs.com/fashion/clothing/daydresses/balenciaga-nicolas-ghesquiere-runway-2010-silk-ikatprint-dress-36/id-v_2553573/

Kendi ününü yayma, tartışma yaratma ve terzilikte uzmanlaşmış olan modanın asi çocuğu olarak kabul edilen Alexander McQueen'in (Watson, 2007:300) tasarımlarında sürrealist etkiler görülmektedir. 2010 ilkbahar/yaz koleksiyonu için hazırlamış olduğu "Plato's Atlantis" isimli koleksiyonunda bask1lı elbiselerde sürrealist etkiler görülmektedir (Görsel 16). Tasarımcının 2011'de Michelle Obama için hazırlamış olduğu giysinin baskılarında da yine sürrealist etkiler mevcuttur (Görsel 17) (Blackman, 2012:377).

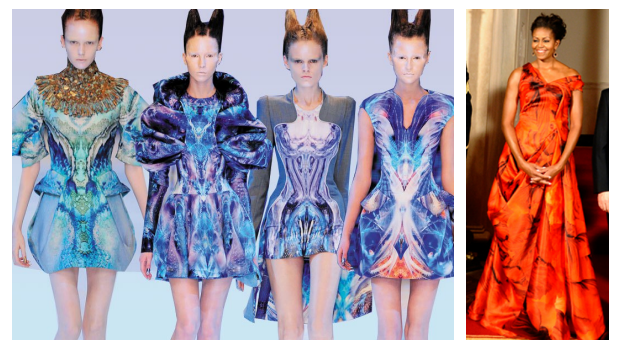

Görsel 16.

https://wdkacollectivecollections.wordpress.com/2015/04/28/ale xanders-plato-atlantis/

Görsel 17. http://resizing.info/imgeffect.html 
Günümüz moda tasarımcılarından Jean-Charles de Castelbajac (Görsel 18), Pedro Lourenço (Görsel 19, 20), Francis Montesinos (Görsel 21-22), Devastee, Iris Van Herpen(Görsel 23) tasarımlarında da sürrealizm etkileri görülmektedir.
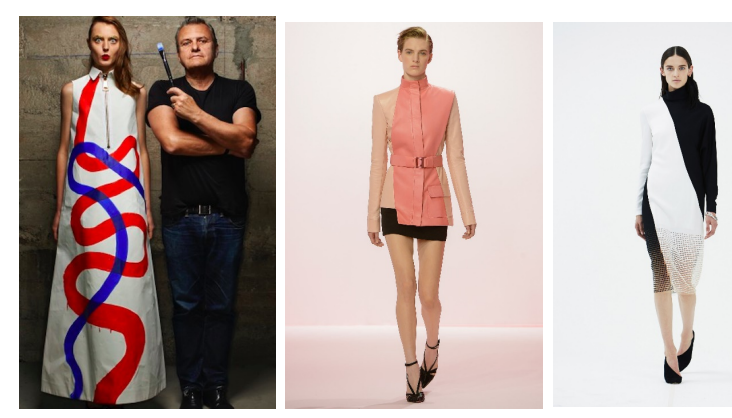

Görsel 18. https://zenitudeprofondelemag.com/jean-charles-decastelbajac

Görsel 19. https://www.vogue.com/fashion-shows/spring-2014ready-to-wear/pedro-lourenco

Görsel 20. https://www.vogue.com/fashion-shows/spring-2014ready-to-wear/pedro-lourenco
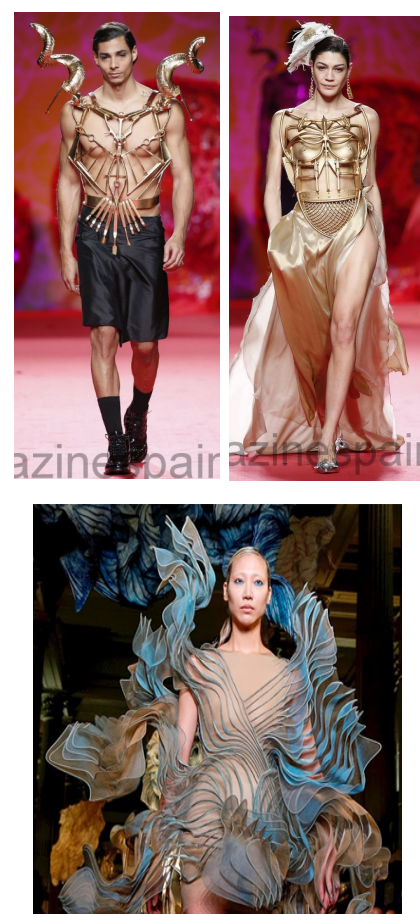

Görsel 21. https://www.magazinespain.com/mercedes-benz-fashinmadrid-2015-francis-montesinos/\#gallery/75341/15876

Görsel 22. https://www.magazinespain.com/mercedes-benz-fashinmadrid-2015-francis-montesinos/\#gallery/75341/158655

Görsel 23. https://www.youtube.com/watch?v=Ox-sy18NuHMM

\section{Sonuç}

Sanayi Devrimiyle birlikte yaşanan gelişmeler, toplumda önemli değişikliklere neden olurken, sanatta da büyük değişikliklere yol açmış ve o dönemden itibaren sanat; modern sanat olarak nitelendirilmeye başlanmıştır. Modern sanatın soyutlamaya yönelik bir eğiliminin olduğu varsayılarak ortaya çıkan akımlardan biri olan "Sürrealizm", gerçeklikten soyutlanarak hayal dünyasından ortaya çıkmış bir akımdir.

Moda da hayal dünyasından ilham alması nedeniyle sürrealizm ve moda aynı kaynaktan beslenmektedir. $\mathrm{Bu}$ nedenle her iki olgu da birbirinden yararlanarak pek çok eser ortaya çıkarmıştır. Sürrealizmin 1924'te resmi olarak ortaya çıkışından sonra, bu akımın temsilcisi olan Salvador Dali, moda tasarımc1sı Elsa Shiaparelli ile birlikte ortak pek çok eser üretmişlerdir. Böylelikle modada sürrealizmin öncüsü Elsa Shiaparelli olmuştur. Schiaparelli'nin öncülüğünü yaptığı modada tasarımlarında sürrealizmden ilham alan tasarımcılar; Cecil Beaton, Erwin Blumenfeld ve George Hoyningen -Huene, kumaş üreticisi Charles Colmbet, Anne Marie of France, Franco Moschino, Pierre Cardin, Vivienne Westwood, Junya Watanabe, Nicolas Ghesquiere, Diane Von Furstenberg, Alexander McQueen, Jean-Charles de Castelbajac, Pedro Lourenço, Francis Montesinos, Devastee, Iris Van Herpen'dir. Kaynak olarak hayal dünyasınından faydalanan sürrealizm ve moda geçmişten günümüze pek çok sanatçı ve tasarımcı birbirleriyle etkileşim içinde bulunmuştur. Aynı kaynağın kullanılması nedeniylede bu etkileşim gelecektede devam edecektir.

\section{Kaynaklar}

Barnard,Malcolm. Sanat, Tasarım ve Görsel Kültür, Çev: Güliz Korkmaz. Ankara: Ütopya Yayınevi,1998.

Blackman, Cally. 100 Years of Fashion. London: Laurence King Publishing Ltd., 2012.

Deonna, W. Sanatta Ritimler ve Kanunlar, Çev.;Süleyman Kazmaz. İstanbul: Remzi Kitapevi,1974.

Dereboy, Jülide. Moda ve 100 Yılın Moda Tasarımcıları, Ankara: Özel Güzel Sanatlar Stilistlik-Moda Ltd. Şti., 2008

Fogg, M. Modanın Tüm Öyküsü, Çev.: Emre Gözgü. İstanbul: Hayalperest Yayınevi, 2014. 
Granger; Michele M. Fashion the industry and its careers. U.S.A: Fairchild Books, A division of Condé Nast Publications, 2007.

Grzymkowski, Eric, Sanat 101, Leonardo Da Vinci'den Andy Warhol'a Sanat Hakkında Bilmeniz Gereken Her Şey, Çeviren: Orhan Düz. İstanbul: Say Yayınları, 2015. İpşiroğlu, Nazan; İpşiroğlu, Mazhar. Oluşum Süreci İçinde Sanatın Tarihi. İstanbul: Hayalperest Yayınevi, 2012.

Kim, Eundeok; Fiore, Ann Marie; Kim, Hyejeong. Fashion Trends, Analysis and Forecasting, Understanding Fashion Series, , New York, U.S.A.: Bloomsbury Publishing, 2011.

Blackman, Cally. 100 Years of Fashion. London: Laurence King Publishing Ltd., 2012.

Koca, Emine; Koç, Fatma. "Giysi Tasarımında Yaratıcıl1k”. e-Journal of New World Sciences Academy, Cilt:4, Say1:1, 33-44,2009.

Koç, Fatma; Şoher, Başak. "Gerçeküstücülük(Sürrealizm) Sanat Akımının Moda Tasarımı Öğrencilerinin Yaratıc1lıklarına Etkisi”, Eğitim Öğretim Araştırmaları Dergisi, Kasım 2015, Cilt:4, Makale No:19 ISSN:2146-9199, 2015.

Koç, Fatma, Emiroğlu, Sümeyya. "Modanın İnşa Alanı Sanat ve Zanaat Hareketinin Paul Poiret Tasarımlarındaki Yansıları", 1.Uluslararası Sanat, Tasarım ve Moda Kongresi/Sanat Etkinlikleri, İKSAD, 20-23 Mayıs 2017 Gaziantep, 244-261, 2017.

Kuru, Songül. Kadın Giyimi Moda Bilim ve Sanat, Uluslararası Multidisipliner Kadın Kongresi, İzmir : 21. Yüzyılın Eşiğinde Kadınlar, Değişim ve Güçlenme, 505-511, 2010.

Mackenzie, Mairi. ...izmler, Modayı Anlamak. İstanbul: Hayal Perest Yayınevi, 2017.

Read, Herbert. Sanatın Anlamı, Çev.: Nuşin Asgari. İstanbul: Hayalperest Yayınevi, 2014.

Özdemir, Ahmet Beyhan; Mutlu, Pınar Boztepe. İcadından Günümüze Portre Fotoğrafında "Yerel Ve Global" Kimlik Kurgusu, SDÜ ART-E Güzel Sanatlar Fakültesi Sanat Dergisi, Kasım/Aralık'17 Cilt: 10 Sayı:20, 652-665, 2017.

Özüdoğru, Şakir. Modern Sanat Akımları ve Moda, İdil Dergisi, Cilt:2, Sayı:6, s:211-238, 2013.
Türker, Halil İbrahim, Çokokumuş, Benan. Gerçeküstücülük, Rene Magritte'den Jerry Uelsmann'a. Sanat ve Tasarım Dergisi, 1 (13), 121-140:2015.

Ünver, Erdem. 2015, İhtiyaçlar, Sorunlar ve Sanat, UHBAB Uluslararası Hakemli Beşeri ve Akademik Bilimler Dergisi, Temmuz/Ağustos/Eylül-Yaz Dönemi, Cilt 4. Sayı:13, ss.188-196, ISSN Print:2147-4168, İstanbul. 2015.

Watson, Linda. "Modaya Yön Verenler", Çev.: Güneş Ayas, Güncel Yayıncılık Ltd. Şti. Ankara: 2007.

\section{Görsel Kaynaklar:}

Görsel

http://www.artribune.com/tribnews/2012/07/arte-e-modaeterne-sorelle-il-mumok-di-vienna-celebra-un-sodaliziovecchio-oltre-un-secolo-con-un-mostra-che-mette-insiemechristo-cindy-sherman-e-salvador-dali-nel-nome-delfashion/attachment/elsa-schiaparelli-salvador-dali-womansdinner-dress-1937-gift-of-mme-elsa-schiaparelli-1969philadelphia-museum-of-art/

Görsel2.http://collections.vam.ac.uk/item/O15655/cra vat-jumper-elsa-schiaparelli/

Görsel3.https://www.pinterest.co.uk/pin/4273494521 $15277480 /$

Görsel4.http://kittyvonpurr.blogspot.com/2010/10/an ne-marie-of-paris-handbags.html

Görsel5.http://kittyvonpurr.blogspot.com/2010/10/an ne-marie-of-paris-handbags.html

Görsel6.https://tr.pinterest.com/pin/47611499182742 $1845 /$

Görsel7.https://www.farfetch.com/tr/shopping/men/ moschino-vintage--less-is-more-gilet-item-11132856.aspx

Görsel8.https://www.flickr.com/photos/azkaged/2450 9381522

Görse19.http://www.thehistorialist.com/2013/09/1971 -joe-garnett-for-records-surrealism.html

Görsel10.http://www.thehistorialist.com/2013/09/197 1-joe-garnett-for-records-surrealism.html

Görsel11.https://www.dezeen.com/2015/03/10/junyawatanabe-aw15-paris-fashion-week-pleats-folds-mathematicalpatterns/ 
Görsel12.http://www.livingly.com/runway/Paris+Fas hion+Week+Fall+2008/Junya+Watanabe/_slhGXGjf_J

Görsel

13.https://nitrolicious.com/2010/01/14/balenciaga-pre-fall-

2010-collection/

\section{Görsel}

14.https://nitrolicious.com/2010/01/14/balenciaga-pre-fall2010-collection/

Görsel15.https://www.1stdibs.com/fashion/clothing/d ay-dresses/balenciaga-nicolas-ghesquiere-runway-2010-silkikat-print-dress-36/id-v_2553573/

\section{Görsel}

16.https://wdkacollectivecollections.wordpress.com/2015/04/2 8/alexanders-plato-atlantis/

Görsel 17.http://resizing.info/imgeffect.html
Görsel 18.https://zenitudeprofondelemag.com/jeancharles-de-castelbajac

Görsel 19.https://www.vogue.com/fashionshows/spring-2014-ready-to-wear/pedro-lourenco

Görsel 20.https://www.vogue.com/fashionshows/spring-2014-ready-to-wear/pedro-lourenco

Görsel21.https://www.magazinespain.com/mercedesbenz-fashin-madrid-2015-francis-

montesinos/\#gallery/75341/15876

Görsel22.https://www.magazinespain.com/mercedesbenz-fashin-madrid-2015-francismontesinos/\#gallery/75341/15865

Görsel 23.https://www.youtube.com/watch?v=Oxsy18NuHM 


\title{
SURREALISM IN FASHION
}

\author{
Başak BOĞDAY SAYĞILI
}

\begin{abstract}
Fashion and art concepts are often used together. The fashion phenomenon emerged from the second half of the 19th century to the day-to-day fashion and artistic interaction, which was the subject of many researchers and researchers. Dress has been prepared according to the principles and methods of design and has begun to relate to art from the turn of a design. This has caused the wearer to be involved in art and be influenced by artistic trends. The purpose of this research; surrealism, one of the artistic trends, is to try to explain with examples the effects of the art movement from the beginning of 1920's until the day when the effects of the art movement began to be seen.
\end{abstract}

Keywords: Fashion, Art, Surrealism, Fashion History 